16.5 per cent sodium acetate was presumably largely due to starvation.

Veterinary Laboratory,

University of Bristol.

Biochemistry Department,

University of Liverpool.

${ }^{1}$ Chari, A., and Wertheimer, E., Nature, 171, 44 (1953).

${ }^{2}$ Reid, R. L., A ust. J. Agric. Res., 1, 338 (1950).

${ }^{3}$ Parnes, J., and Wertheimer, E., Biochem. J., 48, 517. 520 (1950).

- Garner, R. J., and Roberts, R. (unpublished results).

\section{A Method of collecting Fluid leaving the Omasum of Sheep}

IN ruminants a large proportion of the ingested food is digested in the fore-stomachs. In order to know the final result of this digestion, it is necessary to know the composition of the material leaving the fore-stomachs and the rate of flow at the omasoabomasal orifice. To study this problem a special cannula has been devised (Fig. 1). It consists of a main tube, $B$, of ebonite ( $2 \mathrm{~cm}$. internal diameter), into which runs a smaller one, $C(1 \mathrm{~cm}$. internal diameter). The main tube is $10 \mathrm{~cm}$. long and is connected at one end with a funnel, $A$, of which the diameter of the top is $6 \mathrm{~cm}$. and its height $4 \mathrm{~cm}$. The side tube, $C$, is screwed perpendicularly on to the middle of the main tube. It is threaded on the outside over its whole length, so that an ebonite ring $(D)$ of $3 \mathrm{~cm}$. diameter can be screwed on to it, making it mobile over the whole length of the tube.

For the operation, the anæsthetized sheep is put on its left side. The abdominal wall is incised just behind the ribs from the median line about $20 \mathrm{~cm}$. upwards. After opening the abdomen, the abomasum is exposed and a small incision is made in it through which the large tube is slid so that the opening of the funnel fits against the omaso-abomasal orifice, and the main tube lies completely in the abomasal lumen. After screwing the side tube on to the main one, the abomasal wall is sutured. A ligature is put around the abomasum just under the funnel in order to keep the tube in place ; when inserting this ligature, care is taken not to damage the main nerves and blood vessels. It is tightened just sufficiently to prevent the funnel from passing through. Just behind the ribs and next to the main incision a stab wound is made in the abdominal wall through which passes the side tube. The various layers of the abdominal wall are then sutured. The ring is screwed

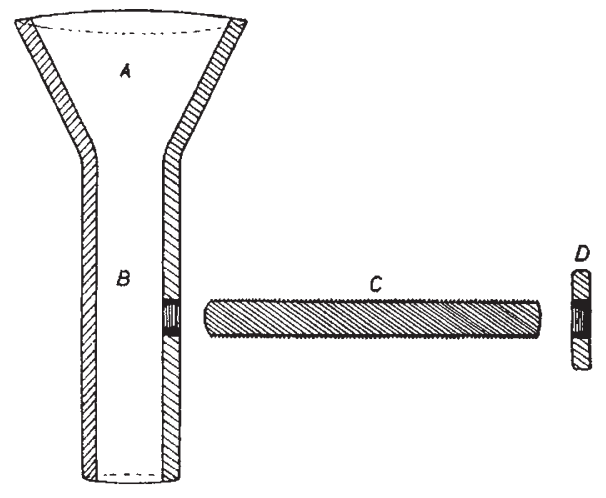

Fig. 1 on the side tube just up to the skin and the tube is corked.

For the collection of fluid leaving the omasum, a balloon is passed through the side tube into the distal part of the main tube, which is blocked by insufflation of air into the balloon. The fluid leaves the side tube at fairly regular intervals; its dry-matter content varies between 5 and 10 per cent. The $p H$ is usually slightly higher than the $p H$ of the ruminal fluid.

Living protozoa are found in the fluid. A very great variation has been found in its chlorine content, although this is always much higher than that of the ruminal fluid. The amount of pepsin, usually present in traces, depends upon the position of the front part of the funnel. It has been shown that the cannula does not interfere with the normal movements of the rumen and reticulum.

More detailed results obtained with this procedure will be published elsewhere.

\section{J. H. Bouckaert}

W. OyamRT

Veterinary College,

Ghent. Sept. 6.

\section{Serous Cells in Brunner's Glands of the Rabbit}

IN Brunner's glands of the rabbit's duodenum there are numerous groups of serous-type cells lying among the mucous acini. It has long been believed that these cells are of a nature similar to those of the pancreatic acini. According to Patzelt ${ }^{1}$, Schwalbe (1872) was the first to make the suggestion, and he quotes the work of later authors who have added confirmatory evidence : the cells have similar staining reactions to those of the pancreatic acini, and they undergo compensatory hypertrophy after the pancreatic duct is ligated; rabbits so treated remain in good health.

In a previous communication ${ }^{2}$, it was pointed out that in sections of rabbit duodenum treated histochemically by Gomori's 'Tween' technique for 'lipase', these serous cells are strongly 'lipase'-positive and stand out sharply among the 'lipase'-negative mucous acinar cells. The suggestion was made that the 'lipase'-positivity might be a point in favour of the above view. This has now been explored further.

It was felt that if it could be shown that the 'lipase' reaction given by these cells is due to true lipase, then the above view would be substantiated very considerably, since true lipase is almost confined to the pancreatic acinar cells. True lipase can be readily distinguished from non-specific esterase by the influence of bile salts upon the activity of the enzyme. It has been demonstrated chemically ${ }^{3}$ and histochemically ${ }^{4}$ that bile salts activate true lipase and inhibit non-specific esterase. This fact formed the basis of the present work.

Specimens of duodenum from each of six rabbits were fixed in absolute acetone, cleared in benzene, embedded in paraffin and serially sectioned at $7 \mu$. A histochemical study was made of the 'lipase' activity of the sections, employing a modification of Gomori's 'Tween' technique , namely, a method in which the sections are introduced directly into the substrate without prior dewaxing ${ }^{b}$. Adjacent sections of each specimen were taken; one was incubated in the usual 'Tween' substrate bath ('Tween 40' was employed throughout) and the other in a 'Tween' substrate bath containing 0.2 per cent sodium 